\title{
Rectangular Ring Open-Ended Monopole Antenna with Inverted L-Strip for WLAN Dual-Band Operations
}

\author{
Joong-Han Yoon ${ }^{*}$, Member, KIICE \\ Department of Electronic Engineering, Silla University, Busan 617-736, Korea
}

\begin{abstract}
A novel design for a simple rectangular ring with open-ended monopole antenna wireless local area network (WLAN) applications is proposed in this article. The proposed antenna consists of an open-ended rectangular ring, an inverted L-strip, and a rectangular slit in the ground plane, and is fed by a $50 \Omega$ microstrip feed-line. Prototypes of the proposed antenna were designed, fabricated, and tested. Experimental results show that the proposed antenna receives $2.3125-2.775 \mathrm{GHz}$ and 4.8625-6.7125 GHz with a return loss less than $-10 \mathrm{~dB}$, covering the required bandwidths of the 2.4/5.2/5.8 GHz WLAN standards. Meanwhile, the 2D radiation patterns and 3D gain performance of the antenna in the operation bands were also observed and discussed.
\end{abstract}

Index Terms: Dual-band operation, Rectangular slit in ground, Ring antenna with open-ended, WLAN antenna

\section{INTRODUCTION}

The development of antenna technology in wireless local area network (WLAN) applications requires high-speed data connectivity, which demands good performance with dual operating frequencies. WLANs and connecting portable terminals have been governed through standardization of frequency bands defined by various standard protocols, namely, IEEE 802.11a (5.15-5.35 GHz and 5.725-5.85 GHz) and $802.11 \mathrm{a} / \mathrm{g}(2.4-2.484 \mathrm{GHz})$. At present, WLAN technology has been one of the most successful and fastest growing wireless communications technologies in the world. Among portable devices, antennas play an important role among the key components in determining radio-frequency (RF) performance of the end product.

As WLAN communication becomes more and more popular, the need for a printed monopole antenna designed with a low profile, light weight, flush mount, and simple structure increases. Recently, multiband antennas for WLAN applications have been reported [1-13]. In particular, a few papers have proposed rectangular ring shaped monopole antennas [14-18]. A microstrip line fed ring antenna with compact structure [14] allows for single band operation only. In our previous study [15], we discussed a rectangular ring with open-ended coplanar waveguide (CPW)-fed antenna for 2.4/5.2 GHz operation. A CPW-fed closed rectangular ring antenna with a vertical strip for WLAN operation was proposed [16]. Also, a CPW-fed folded loop antenna for satellite DMB operation was proposed [17], and a CPW-fed folded monopole antenna with two symmetry strip arms for WLAN operation was also proposed [18].

In this study, a novel rectangular ring with an open-ended monopole antenna with an inverted L-strip suited for dualband WLAN applications was designed. The proposed

Received 10 July 2012, Revised 07 September 2012, Accepted 17 September 2012

*Corresponding Author E-mail: jhyoon@silla.ac.kr

(c) This is an Open Access article distributed under the terms of the Creative Commons Attribution Non-Commercial License (http://creativecommons.org/li-censes/by$\mathrm{nc} / 3.0 /$ ) which permits unrestricted non-commercial use, distribution, and reproduction in any medium, provided the original work is properly cited. 
antenna comprises a rectangular ring with an open-ended, inverted L-strip, and a rectangular slit in the ground plane. By properly selecting the dimensions of the proposed antenna, good dual broadband bandwidth and radiation characteristics suitable for WLAN 2.4/5.2/5.8 GHz operations can be achieved. The detailed design considerations and experimental results of the proposed monopole antenna for WLAN operation are presented and discussed below.

\section{ANTENNA DESIGN}

Fig. 1 shows the geometry of the proposed WLAN monopole antenna for achieving dual band frequency operation. In this design, the total size of the substrate was $46.4 \times 50 \mathrm{~mm}\left(\mathrm{~W}_{10} \times \mathrm{L}_{8}\right)$. The proposed antenna was fabricated on one side of an inexpensive FR4 substrate with relative permittivity of 4.4 and a substrate thickness of 1.0 $\mathrm{mm}$. The radiating element of the proposed antenna, with dimensions of $32.2 \times 23.8 \mathrm{~mm}\left(\mathrm{~W}_{1} \times \mathrm{L}_{1}\right)$, is an open-ended symmetrical rectangular ring that has a uniform width $\left(\mathrm{L}_{7}\right)$ of $2 \mathrm{~mm}$ for design convenience. The ground plane with the size of $46.4 \times 18.0 \mathrm{~mm}\left(\mathrm{~W}_{10} \times \mathrm{L}_{3}\right)$, is placed on the other side of the substrate. In this design, the rectangular ring was open-endedtoprovideresonancewith2.4GHzbands. A $50 \Omega$ microstrip feed line, $W_{7}=2 \mathrm{~mm}$, is used for centrally feeding the antenna from the bottom edge of the symmetrical rectangular ring. To obtain good impedance matching and a wide bandwidth for operating frequencies, we introduced the inverted L-strip, $12.0 \times 3.8 \mathrm{~mm}\left(\mathrm{~W}_{4} \times\right.$ $\left.\left(\mathrm{L}_{5}+\mathrm{L}_{6}\right)\right)$, and the rectangular slit, $4.0 \times 10.0 \mathrm{~mm}\left(\mathrm{~W}_{9} \times\right.$ $\mathrm{L}_{4}$ ), in the ground plane. The inverted L-strip is centrally posi-tioned at the bottom edge of the rectangular ring. The rec-tangular slit is top centrally located on in the ground plane. These geometry parameters of the proposed antenna are optimized using commercially available simulation software, Ansoft's high frequency structure simulator (HFSS) [19].

Fig. 2 shows the block diagram of the antenna design process. First of all, we have to define the specification of the antenna design suitable for user needs. Next, we verify the space of the antenna in the system and select the simulation tool. Next, we select the material of the antenna substrate. It is very important to select the material in the antenna design because the antenna substrate heavily affects the antenna performance. Next, we design the antenna structure (feed ground size, layers, etc.) using the antenna simulation tool. If the antenna specifications are satisfied, we can make the simulated antenna from the optimized parameters. However, if the antenna specifications are not satisfied, we carry out a resimulation of the proposed antenna. Finally, we can make the proposed antenna from the optimized parameters satisfied requirement.

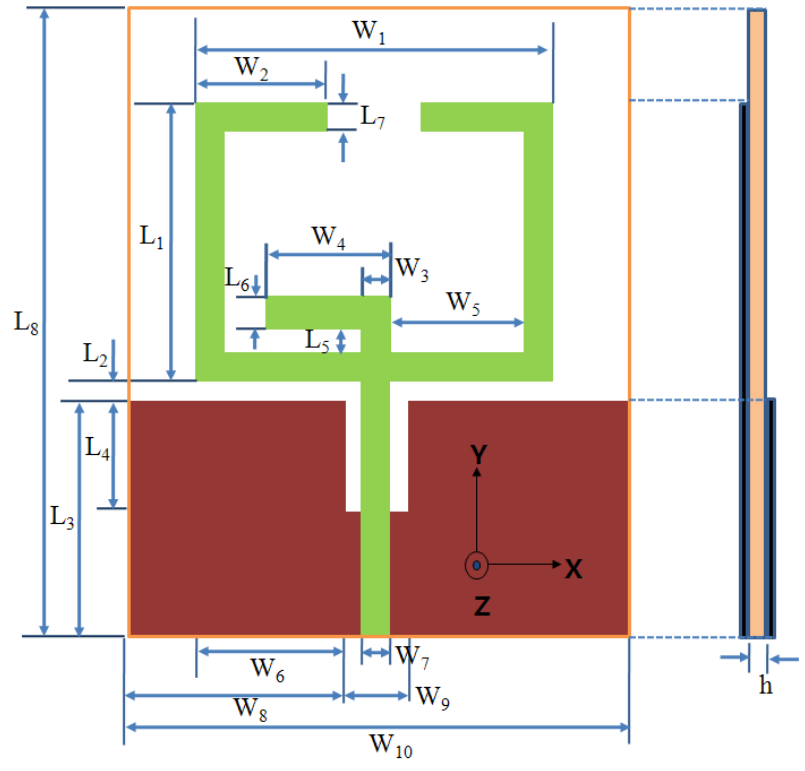

Fig. 1. Configuration of the open-ended microstrip-fed monopole antenna, an inverted L-strip, and a rectangular slit in the ground plane.

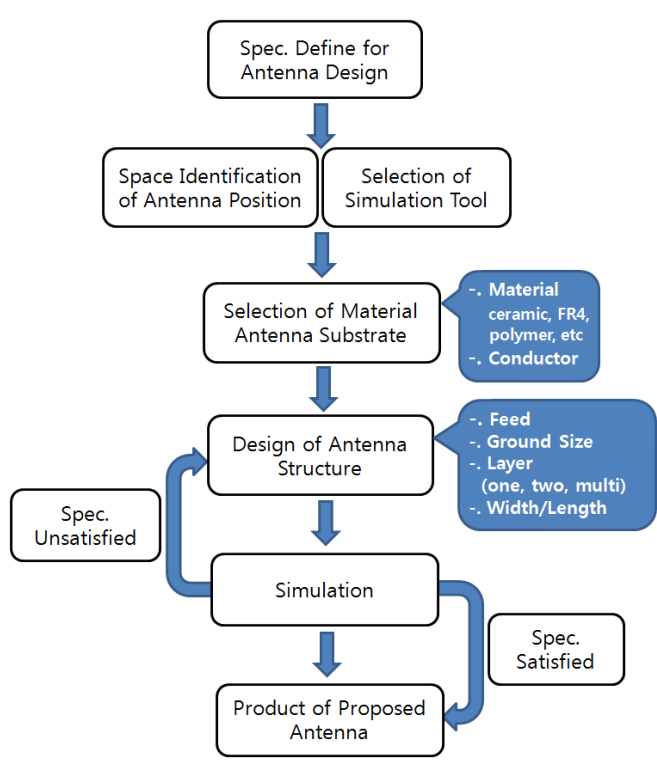

Fig. 2. Block diagram of a brief antenna design process.

\section{A. Effect of Open-Ended Rectangular Ring, $W_{2}$}

Fig. 3 shows the return loss for different values of length $\mathrm{W}_{2}$. In the 2.4 and $5 \mathrm{GHz}$ bands, it can be seen in the figure that the impedance bandwidth and return loss characteristics did slightly change when $\mathrm{W}_{2}$ was varied from 11.8 to 13.8 $\mathrm{mm}$. It can be seen in the figure, however, that when $\mathrm{W}_{2}$ is 
$12.8 \mathrm{~mm}$, the return loss characteristics are better than when $\mathrm{W}_{2}$ is 11.8 or $13.8 \mathrm{~mm}$. Also, when $\mathrm{W}_{2}$ is $12.8 \mathrm{~mm}$, the impedance bandwidth satisfied the desired $5 \mathrm{GHz}$ frequency band. Thus, to design an optimal dual-band WLAN operation, $\mathrm{W}_{2}$ was set at $12.8 \mathrm{~mm}$.

\section{B. Effect of Gap between Ground Plane and Open-Ended Rectangular Ring, $W_{10}$}

Fig. 4 shows the return loss for different values of length $\mathrm{W}_{10}$. In the 2.4 and $5 \mathrm{GHz}$ bands, it can be seen in the figure that the impedance bandwidth and return loss characteristics did slightly change when $\mathrm{W}_{10}$ was varied from 40.4 to 46.4 $\mathrm{mm}$. It can be seen in the figure, however, that when $\mathrm{W}_{10}$ is $46.4 \mathrm{~mm}$, the impedance bandwidth of the return loss satisfied the desired $5 \mathrm{GHz}$ frequency band. In these cases $\left(\mathrm{W}_{10}=40.4,42.4,44.4 \mathrm{~mm}\right)$, the impedance bandwidth did not satisfy the desired $5 \mathrm{GHz}$ frequency band. Thus, to design an optimal dual-band WLAN operation, $\mathrm{W}_{10}$ was set at $46.4 \mathrm{~mm}$.

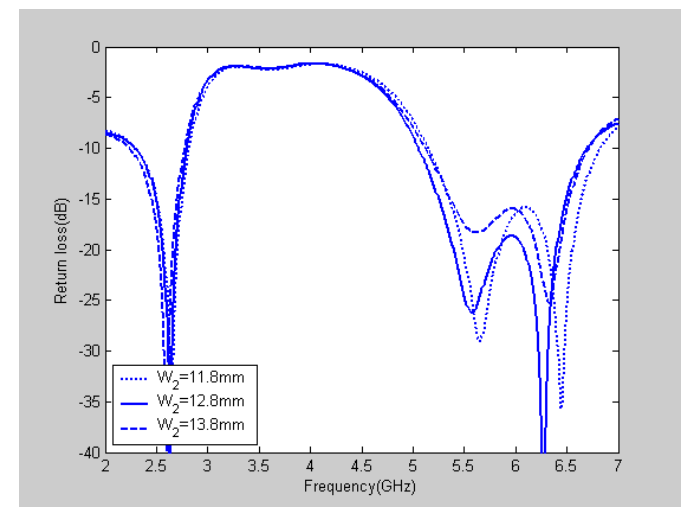

Fig. 3. Simulated return loss of the proposed antenna with different values, $\mathrm{W}_{2}$.

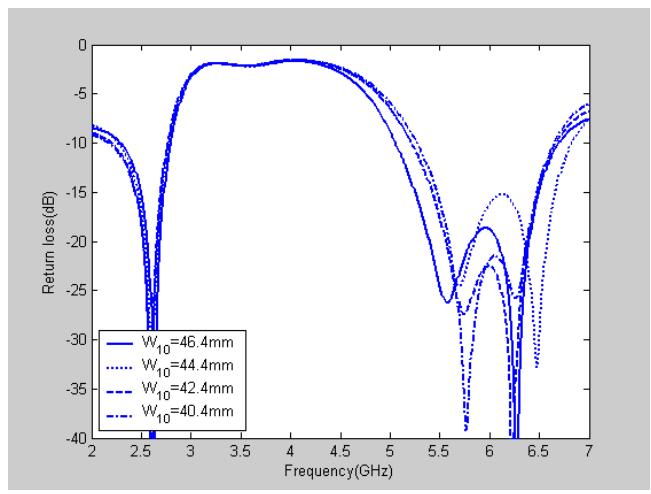

Fig. 4. Simulated return loss of the proposed antenna with varying values, $\mathrm{W}_{10}$.

\section{Effect of Inverted L-Strip}

An inverted L-strip was introduced into the open-ended rectangular ring to alter the input impedance characteristics. Fig. 5 shows the return loss with and without an inverted Lstrip in the open-ended rectangular ring. The impedance bandwidth and return loss characteristics worsened when there was no an inverted L-strip in the open-ended rectangular ring. This indicates that the inverted L-strip play an important role in impedance matching of the proposed antenna. The optimal values of the inverted L-strip width $\left(\mathrm{L}_{6}\right)$ and length $\left(\mathrm{W}_{4}\right)$ were determined. Thus, to design a good dual-band WLAN operation, $\mathrm{W}_{4}$ was set at $12.0 \mathrm{~mm}$, and $\mathrm{L}_{6}$ was set at $2.0 \mathrm{~mm}$.

\section{Effect of the Rectangular Slit in the Ground Plane}

To realize the dual-band WLAN operation, a rectangular slit in the ground plane was introduced into the ground plane to alter the input impedance characteristics. Fig. 6 shows the return loss with and without a slit in the ground. It can be seen in the figure that the resonant frequency was not generated in the $5 \mathrm{GHz}$ bands and that the impedance bandwidth and return loss characteristics worsened when there was no rectangular slit in the ground plane. This indicates that the return loss of the proposed antenna in the 5 $\mathrm{GHz}$ bands heavily depends on the rectangular slit in the ground plane. The optimal values of the rectangular slit width $\left(\mathrm{W}_{9}\right)$ and length $\left(\mathrm{L}_{4}\right)$ were determined. To design a dual-band WLAN antenna, $\mathrm{W}_{9}$ was set at $4.0 \mathrm{~mm}$, and $\mathrm{L}_{4}$ was set at $10.0 \mathrm{~mm}$. Certainly, with the variation of the width and length in the rectangular slit, the return loss can be controlled at less than return loss $-10 \mathrm{~dB}$, thus covering the frequency bandwidth for WLAN (2.4-2.484, 5.15-5.35, and $5.75-5.85 \mathrm{GHz}$ ).

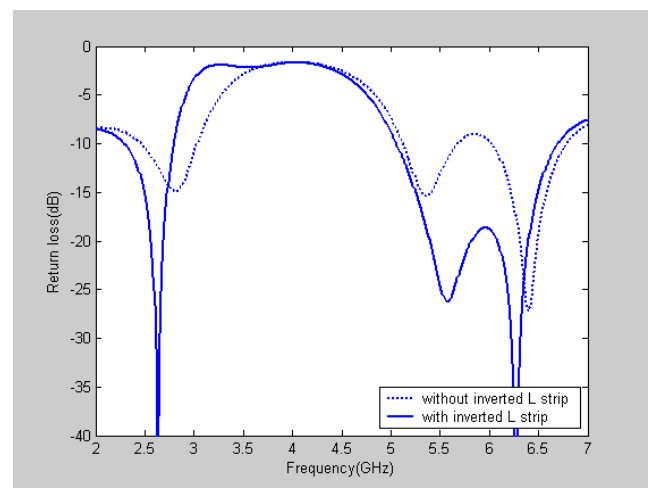

Fig. 5. Simulated return loss of the proposed antenna with and without an inverted L-strip. 


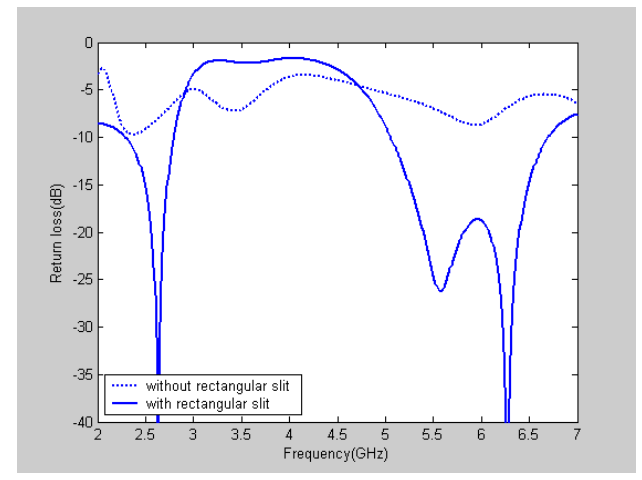

Fig. 6. Simulated return loss of the proposed antenna with and without a rectangular slit in the ground.

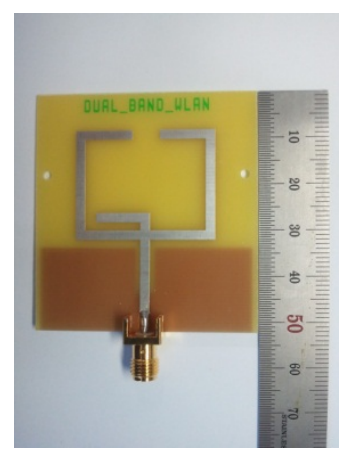

(a)

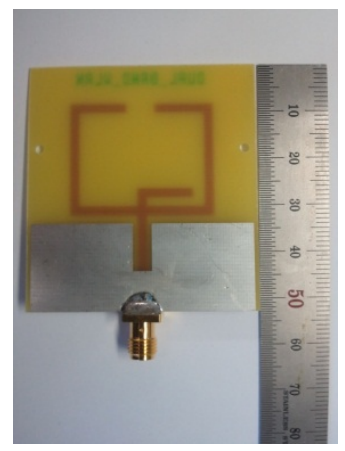

(b)
Fig. 7. Prototype of the proposed dual-band antenna: (a) front view and (b) back view.

The proposed antenna structure has several design parameters that can handle the resistance and reactance of the antenna input impedance. As such, the dimensions of the proposed antenna were set. as follows: $\mathrm{W}_{1}=32.2 \mathrm{~mm} ; \mathrm{W}_{2}=$ $12.8 \mathrm{~mm} ; \mathrm{W}_{3}=2.0 \mathrm{~mm} ; \mathrm{W}_{4}=12.0 \mathrm{~mm} ; \mathrm{W}_{5}=13.2 \mathrm{~mm} ; \mathrm{W}_{6}$ $=14.0 \mathrm{~mm} ; \mathrm{W}_{7}=2.0 \mathrm{~mm} ; \mathrm{W}_{8}=21.2 \mathrm{~mm} ; \mathrm{W}_{9}=4.0 \mathrm{~mm}$; $\mathrm{W}_{10}=46.4 \mathrm{~mm} ; \mathrm{L}_{1}=23.8 \mathrm{~mm} ; \mathrm{L}_{2}=1.7 \mathrm{~mm} ; \mathrm{L}_{3}=18.0 \mathrm{~mm}$; $\mathrm{L}_{4}=10.0 \mathrm{~mm} ; \mathrm{L}_{5}=1.8 \mathrm{~mm} ; \mathrm{L}_{6}=2.0 \mathrm{~mm} ; \mathrm{L}_{7}=2.0 \mathrm{~mm} ; \mathrm{L}_{8}=$ $50.0 \mathrm{~mm}$; and $\mathrm{H}=1.0 \mathrm{~mm}$. Based on the design dimensions, the proposed compact antenna was constructed and tested. A prototype of the proposed antenna was fabricated with the aforementioned design parameters and is shown in Fig. 7a and $b$.

\section{MEASUREMENT \& RESULTS}

A prototype of the optimized antennas was fabricated and the return loss, radiation pattern, and gain were measured. The frequency response of the return loss of the proposed antenna was measured using an Anritsu MS4644A vector network analyzer at Silla University. Fig. 8 shows the measured and simulated return loss of the proposed antenna for multi-operating wireless communication applications. The results demonstrate that they have a generally acceptable agreement. It can be seen in the figure that a slight difference exists between the simulation and measurement results. This is probably due to the influence of the cable connected to the fabricated antenna in the measurement procedure.

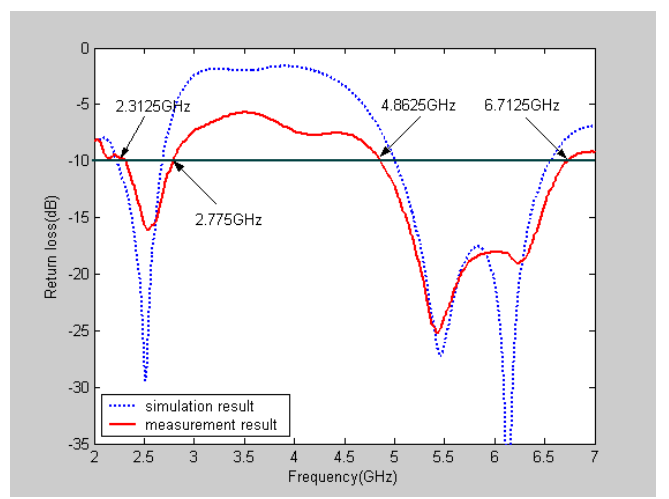

Fig. 8. Simulated and measured return loss versus the frequencies of the proposed antenna.

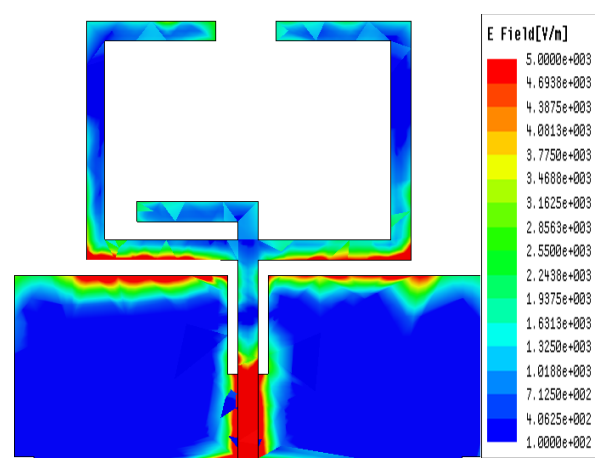

(a)

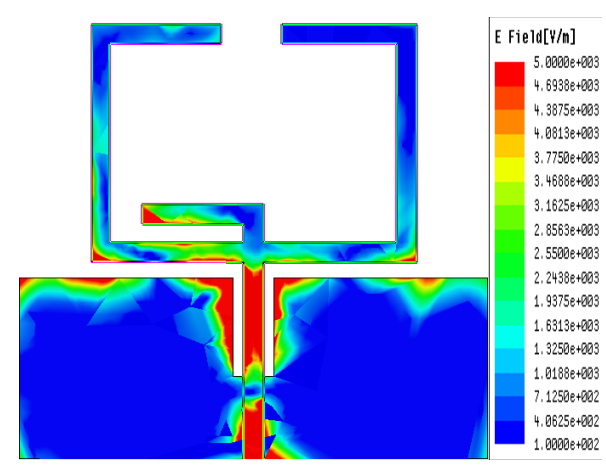

(b)

Fig. 9. Surface current distributions at $2.625 \mathrm{GHz}$ (a) and $5.575 \mathrm{GHz}$ (b). 


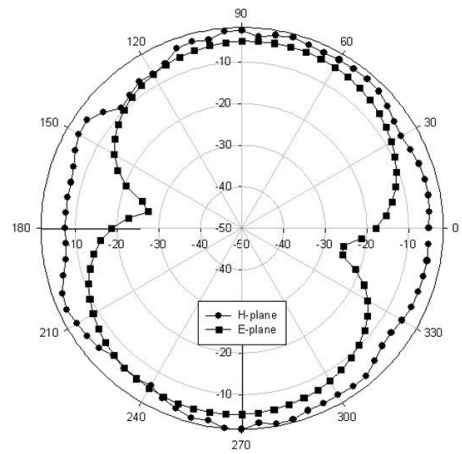

(a)

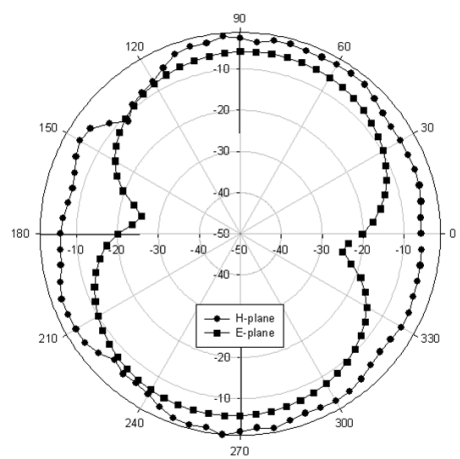

(b)

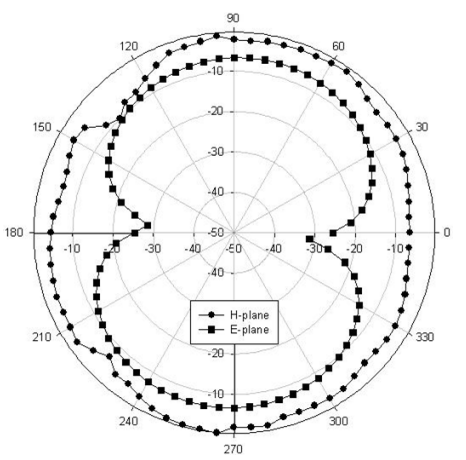

(c)

Fig. 10. Radiation patterns of the proposed antenna at $2.4 \mathrm{GHz}$ (a), $2.44 \mathrm{GHz}$ (b), and $2.48 \mathrm{GHz}$ (c) in the E-plane and H-plane.

There are two resonant modes that are excited at about 2.5375 and $5.425 \mathrm{GHz}$ with wide impedance bandwidths. The lowest resonant mode has a $10 \mathrm{~dB}$ impedance bandwidth of $462.5 \mathrm{MHz}(2.3125-2.775 \mathrm{GHz})$, which covers the $2.4 \mathrm{GHz}$ WLAN bands. The second resonant mode has an impedance bandwidth of 1,850 MHz (4.8625-6.7215 GHz), which satisfies the required bandwidth of the $5.2 / 5.8 \mathrm{GHz}$ WLAN bands. Clearly, the design prototype of the proposed antenna has sufficient bandwidth to cover the needs of the 2.4 and $5 \mathrm{GHz}$ WLAN bands (2.4-2.484 and 5.15-5.825 $\mathrm{GHz}$, respectively). Theoretically, HFSS was used to evaluate and verify the two resonant frequencies 2.625 and $5.575 \mathrm{GHz}$, which mainly depended on the lengths of the

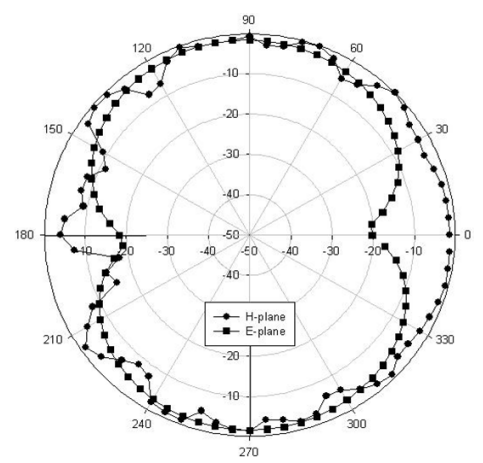

(a)

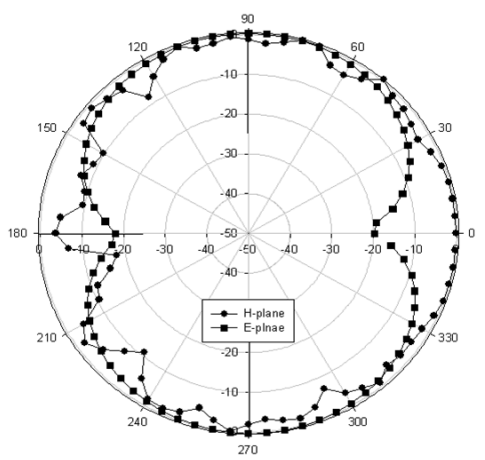

(b)

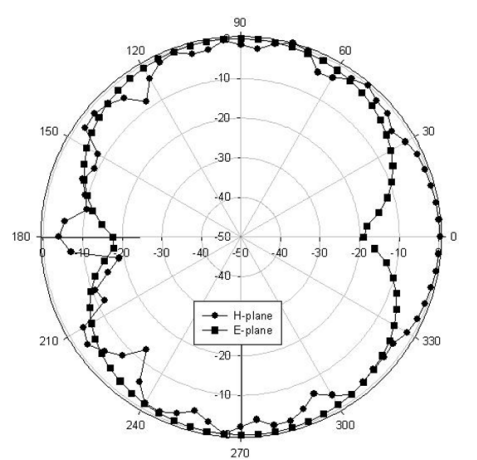

(c)

Fig. 11. Radiation patterns of the proposed antenna at $5.15 \mathrm{GHz}(\mathrm{a})$, 5.3 GHz (b), and $5.35 \mathrm{GHz}$ (c) in the E-plane and $\mathrm{H}$-plane.

open-ended rectangular ring and rectangular slit in the ground plane. As expected, it was obvious that different surface currents were excited by the 2.625 and $5.575 \mathrm{GHz}$ frequencies.

Fig. 9a and b show the surface current density excitations along the open-ended rectangular ring and rectangular slit in the ground plane in the cases of the two resonant frequencies 2.625 and $5.575 \mathrm{GHz}$, respectively. As shown in Fig. 9a, the $2.4 \mathrm{GHz}$ band surface current density excitations along the open-ended rectangular ring was observed when the resonant frequency was $2.625 \mathrm{GHz}$. Thus, it can be inferred that the $2.4 \mathrm{GHz}$ band excitation is mainly contributed by the open-ended rectangular ring. As shown in 
Fig. 9b, however, larger surface current densities flowed not only around the rectangular slit in the ground plane but also along the inverted L-strip when the resonant frequency was $5.575 \mathrm{GHz}$. Thus, it can be inferred that the $5 \mathrm{GHz}$ band excitation is mainly contributed by the rectangular slit in the ground plane.

Fig. 10 shows the measured $2 \mathrm{D}$ far-field radiation patterns in the E-plane ( $\mathrm{x}-\mathrm{z}$ plane) and H-plane (y-z plane) at 2.4, 2.44, and $2.48 \mathrm{GHz}$ bands. Fig. 11 shows the measured 2D far-field radiation patterns in the E-plane ( $\mathrm{x}$-z plane) and $\mathrm{H}$-plane (y-z plane) at 5.15, 5.3, and 5.35 GHz bands.

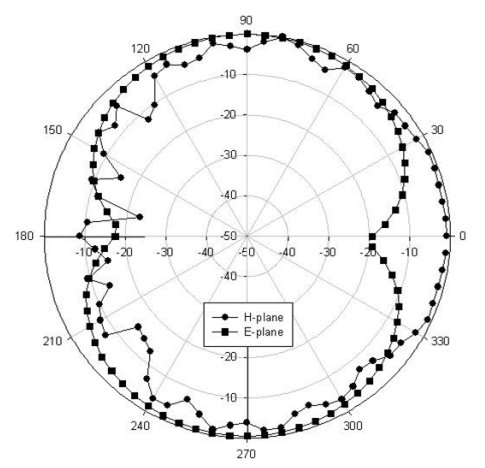

(a)

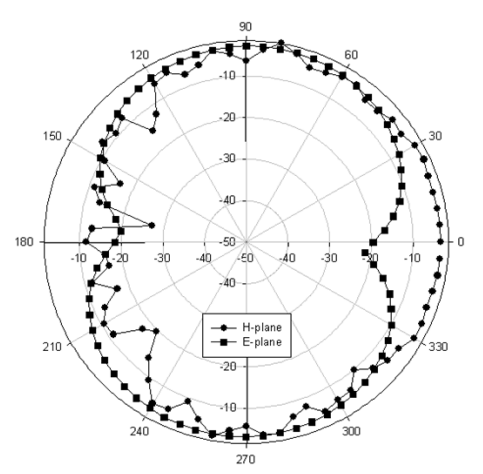

(b)

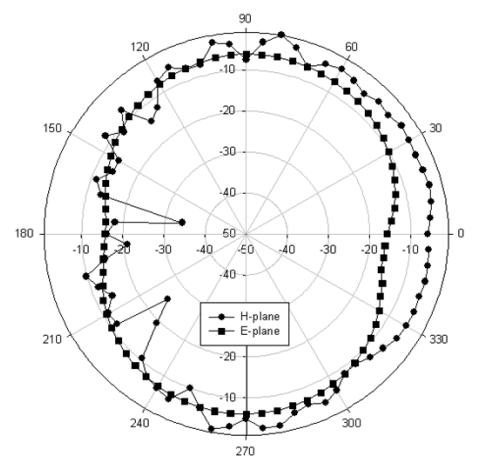

(c)

Fig. 12. Radiation patterns of the proposed antenna at $5.7 \mathrm{GHz}(\mathrm{a})$, $5.75 \mathrm{GHz}(\mathrm{b})$, and $5.9 \mathrm{GHz}(\mathrm{c})$ in the E-plane and $\mathrm{H}$-plane.

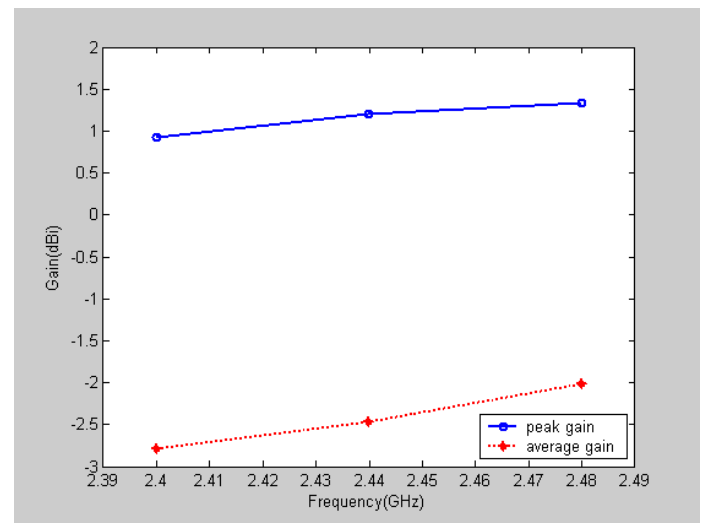

(a)

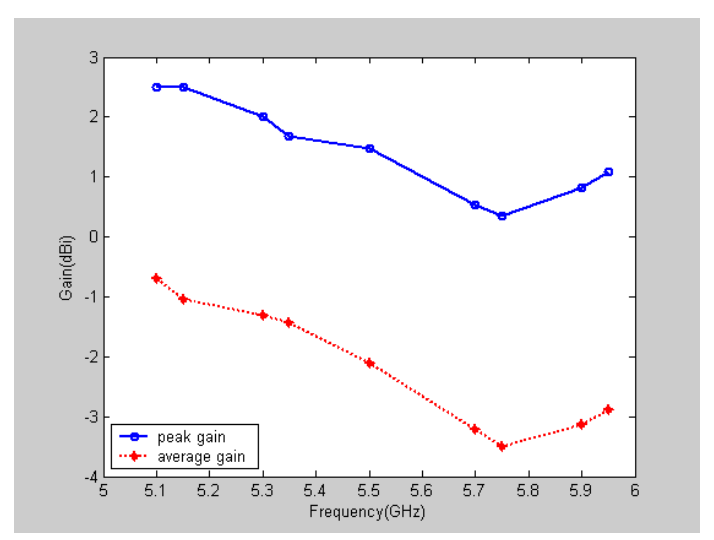

(b)

Fig. 13. Measured antenna peak and average gains for the following operating frequencies: (a) $2.4 \mathrm{GHz}$ band and (b) $5 \mathrm{GHz}$ band.

Fig. 12 shows the measured 2D far-field radiation patterns in the E-plane ( $\mathrm{x}-\mathrm{z}$ plane) and $\mathrm{H}$-plane ( $\mathrm{y}-\mathrm{z}$ plane) at the 5.7, 5.75, and $5.9 \mathrm{GHz}$ bands. From a view of these radiation patterns, the proposed antenna displays omnidirectional radiation characteristics in the $\mathrm{H}$-plane and monopole-like radiation pattern characteristics in the Eplane at the frequencies considered.

Fig. 13a and b show the 3D measured antenna peak and average gain for the frequencies across the 2.4 and $5 \mathrm{GHz}$ bands. The $2.4 \mathrm{GHz}$ band had an antenna peak gain level of about $0.93-1.33 \mathrm{dBi}$ (Fig. 13a), and the $5 \mathrm{GHz}$ band, about 0.34-2.50 dBi (Fig. 13b). The $2.4 \mathrm{GHz}$ band had an antenna average gain level of about -2.79-2.02 dBi (Fig. 13a), and the $5 \mathrm{GHz}$ band, about 3.50-0.69 dBi (Fig. 13b). The 3D antenna gain had a peak value of $1.20 \mathrm{dBi}$ at $2.44 \mathrm{GHz}$. At $5.15 \mathrm{GHz}$, the 3D maximum peak gain was $2.49 \mathrm{dBi}$; at 5.5 $\mathrm{GHz}, 1.47 \mathrm{dBi}$ and at $5.9 \mathrm{GHz}, 0.82 \mathrm{dBi}$. As a result, the gain of the proposed antenna within the operating bands satisfies the requirements for WLAN systems. 


\section{CONCLUSIONS}

This article proposed a simple planar monopole antenna for dual-band WLAN operation. With an open ended rectangular ring, inverted L-strip, and a rectangular slit in the ground plane, the impedance bandwidth needed to meet the requirements of WLAN in the $2.4 / 5.2 / 5.8 \mathrm{GHz}$ bands were achieved. Various parameters of the proposed antenna were optimized via simulation (HFSS), and tested. Parametric studies of the proposed antenna were conducted, and the mechanisms of the dual-band operation were discussed. This proposed monopole antenna had $-10 \mathrm{~dB}$ impedance bandwidths of about 462.5 and 1,850 MHz (2.3125-2.775 and $4.8625-6.7125 \mathrm{GHz}$ ) or about $18.2 \%$ and $31.97 \%$. The experiment results showed that good impedance matching was achieved. Omnidirectional radiation pattern characteristics for frequencies over the WLAN bands were also obtained for the proposed antenna. The proposed antenna's measured peak gain varied between 0.34 and $2.50 \mathrm{dBi}$. Because of its low cost, lightweight, and compact size, the antenna is very suitable for WLAN applications. Next, broad and multiband antenna for wireless communication applications should be investigated.

\section{ACKNOWLEDGMENTS}

Author would like to thank Director S. G. Lee and Jeffrey Park, senior engineer at the R\&D Center of Foxconn Corporation in Korea, for the assistance in the measurement of antenna radiation patterns.

\section{REFERENCES}

[1] Y. Liu, Z. Niu, and X. Wang, "Dual-band H-shaped slot antenna for 2.4 and $5 \mathrm{GHz}$ wireless communication,” Microwave and Optical Technology Letters, vol. 52, no. 4, pp. 957-959, 2010.

[2] S. W. Su and F. S. Chang, "Compact, printed mobile-unit antenna for 2.4 and 5 GHz WLAN applications,” Microwave and Optical Technology Letters, vol. 52, no. 12, pp. 2648-2653, 2010.

[3] M. Harmouzi and M. Essaaidi, "A novel compact dual-band antenna for IEEE $802.11 \mathrm{a} / \mathrm{b} / \mathrm{g} / \mathrm{n}$ WLAN,” Microwave and Optical Technology Letters, vol. 53, no. 2, pp. 315-317, 2011.

[4] W. S. Chen, B. Y. Lee, and P. Y. Chang, "A compact and small printed monopole antenna for WLAN applications,” Microwave and Optical Technology Letters, vol. 53, no. 7, pp. 1518-1522, 2011.

[5] W. C. Chen and Y. Dai, “A dual-band shorted monopole antenna for WLAN-band application,” Microwave and Optical Technology Letters, vol. 53, no. 9, pp. 2142-2145, 2011.

[6] T. C. Hong and S. W. Su, "Novel, one-piece, metal-plate loop-like antenna with symmetrical structure for thin LCD TV applications in the 2.4/5.2/5.8 GHz WLAN bands," Microwave and Optical Technology Letters, vol. 53, no. 10, pp. 2232-2238, 2011.

[7] N. Zhang, Y. J. Wang, and X. W. Shi, “Compact dual-band-printed dipole antenna with parallel-winding lines and tapered structure for WLAN applications,” Microwave and Optical Technology Letters, vol. 53, no. 11, pp. 2492-2494, 2011.

[8] S. A. Rahim, Z. Nor, N. M. Jizat, M. Sabran, and M. F. Jamlos, "Dual-band printed monopole slot antenna with combination of Lslot and ARM-slot for WLAN application,” Microwave and Optical Technology Letters, vol. 53, no. 11, pp. 2668-2673, 2011.

[9] W. C. Liu and Y. L. Chen, "Compact strip-monopole antenna for WLAN-band USB dongle application,” Electronics Letters, vol. 47, no. 8, pp. 479-480, 2011.

[10] S. W. Su, "Compact, printed, dual-feed, shorted monopole antenna for concurrent 2.4- and 5-GHz WLAN operation,” Microwave and Optical Technology Letters, vol. 54, no. 1, pp. 188-193, 2012.

[11] Y. J. Wang, Z. Y. Lei, N. Zhang, D. S. Cai, and Y. F. Wang, "Asymmetric-arm printed dipole antenna for WLAN applications," Microwave and Optical Technology Letters, vol. 54, no. 2, pp. 354358, 2012.

[12] X. Sun, S. W. Cheung, and T. I. Yuk, "Coplanar waveguide-fed dual-band antenna for wireless local area network applications,” Microwave and Optical Technology Letters, vol. 54, no. 6, pp. 1391-1396, 2012.

[13] R. H. Li, X. W. Shi, N. Zhang, Y. F. Wang, and Y. J. Wang, “A novel compact dual-band antenna for WLAN applications," Microwave and Optical Technology Letters, vol. 54, no. 6, pp. 1476-1479, 2012.

[14] W. C. Liu, “Compact microstrip-line-fed ring monopole antenna with tuning strip for $5 \mathrm{GHz}$ WLAN operation,” Electronics Letters, vol. 41, no. 15, pp. 831-832, 2005.

[15] J. H. Yoon, "Fabrication and measurement of rectangular ring with open-ended CPW-fed monopole antenna for 2.4/5.2-GHz WLAN operation,” Microwave and Optical Technology Letters, vol. 48, no. 8, pp. 1480-1483, 2006.

[16] L. Zhang, Y. C. Jiao, G. Zhao, Y. Song, and F. S. Zhang, "Broadband dual-band CPW-fed closed rectangular ring monopole antenna with a vertical strip for WLAN operation,” Microwave and Optical Technology Letters, vol. 50, no. 7, pp. 1929-1931, 2008.

[17] S. I. Park, "Design of planar-type modified folded loop antennas," International Journal of Maritime Information and Communication Sciences, vol. 8, no. 5, pp. 489-492, 2010.

[18] Y. Seo, J. Jung, H. Lee, and Y. Lim, "Modified dual monopole antenna for WLAN operation,” Microwave and Optical Technology Letters, vol. 53, no. 12, pp. 2768-2770, 2011.

[19] ANSYS Inc., ANSYS HFSS [Internet], Available: http://www. ansoft.com/products/hf/hfss. 


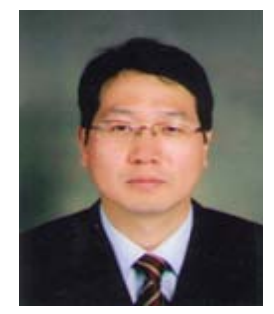

\section{Joong-Han Yoon}

received his B.S., M.S., and Ph. D. degrees in electronics engineering from Inha University, Incheon, South Korea, in 1994, 1996, and 2003, respectively. From 2003, he was a Post-doc at Inha University. From November 2004, to October 2005, he was a Post-doc at Yokohama National University, Yokohama, Japan. From November 2005, to August 2008, he was a Senior Engineer at Samsung Electro-Mechanics, Suwon, Gyeonggi-do, Korea. From September 2008, he joined the faculty of the Department of Electronic Engineering, Silla University, Busan, Korea. His research interests include mobile antennas, RFID, and digital radar 